\title{
Analysis of Inflammatory Mediators in Prediabetes and Newly Diagnosed Type 2 Diabetes Patients
}

\author{
Zhen Wang, ${ }^{1}$ Xu-Hui Shen, ${ }^{2}$ Wen-Ming Feng, ${ }^{3}$ Guo-fen Ye, ${ }^{4}$ Wei Qiu, ${ }^{5}$ and Bo Li ${ }^{6}$ \\ ${ }^{1}$ Department of Clinical Medicine, School of Nursing \& Medicine, Huzhou University, Huzhou, Zhejiang 313000, China \\ ${ }^{2}$ Department of Nursing Medicine, School of Nursing \& Medicine, Huzhou University, Huzhou, Zhejiang 313000, China \\ ${ }^{3}$ Surgery Department, Huzhou Wu Xing People's Hospital, Huzhou, Zhejiang 313008, China \\ ${ }^{4}$ Physical Examination Center, Zhebei Clinical Medicine Hospital, Huzhou University, Huzhou, Zhejiang 313000, China \\ ${ }^{5}$ Endocrinology Department, Zhebei Clinical Medicine Hospital, Huzhou University, Huzhou, Zhejiang 313000, China \\ ${ }^{6}$ Huanzhu Street Community Health Center, Huzhou, Zhejiang 313000, China
}

Correspondence should be addressed to Xu-Hui Shen; shxh1218@zjhu.edu.cn

Received 12 April 2016; Accepted 5 June 2016

Academic Editor: Jixin Zhong

Copyright (C) 2016 Zhen Wang et al. This is an open access article distributed under the Creative Commons Attribution License, which permits unrestricted use, distribution, and reproduction in any medium, provided the original work is properly cited.

\begin{abstract}
This study evaluated the inflammatory markers in prediabetes and newly diagnosed type 2 diabetes mellitus (T2DM). Inflammatory markers levels were analyzed using one-way analysis of covariance and the association with prediabetes or T2DM risks was examined by logistic regression models. Our data showed increased levels of hypersensitivity C-reactive protein (hs-CRP), interleukin (IL-4), IL-10, and tryptase in prediabetes subjects and hs-CRP, immunoglobulin E (IgE), IL-4, and IL-10 in T2DM subjects. We concluded that Hs-CRP, IgE, IL-4, IL-10, and tryptase were positively associated with prediabetes or T2DM. Further large prospective studies are warranted to assess a temporal relation between inflammatory biomarkers and incidence of prediabetes or T2DM and its associated chronic diseases.
\end{abstract}

\section{Introduction}

Type 2 diabetes mellitus (T2DM) is a complex disease in which both genetic and environmental factors interact in determining impaired $\beta$-cell insulin secretion and peripheral insulin resistance [1-3]. T2DM is also a metabolic disorder between pro- and anti-inflammatory characterized by chronic hyperglycemia and increased or decreased levels of circulating cytokines [4]. The rise in the proinflammatory cytokines (e.g., interleukin- (IL-) 1, IL-6, tumor necrosis factor- (TNF-) $\alpha$, C-reactive protein (CRP), transforming growth factor- (TGF-) $\beta$, and leptin) or the fall in antiinflammatory cytokines (e.g., interleukin-1 receptor antagonist (IL-1Ra), IL-4, IL-10, IL-13, and adiponectin) is the essential step in glucotoxicity and lipotoxicity induced mitochondrial injury, oxidative stress, and beta cell apoptosis in T2DM [2-4]. These pro- and anti-inflammatory cytokines can enhance insulin resistance directly in adipocytes, muscle, and hepatic cells, leading to systemic disruption of insulin sensitivity and impaired glucose homeostasis [5].
Many single nucleotide polymorphisms (SNPs) in various genes including those of pro- and anti-inflammatory cytokines have been reported as a risk for T2DM [1-3]. But not all SNPs have been confirmed by unifying results in different studies and wide variations have been reported in various ethnic groups [2-4]. Genetic polymorphisms of Creactive protein (CRP) and their association with prediabetes and T2DM have been widely studied [5]. IL-6 was regarded as a kind of pro- and anti-inflammatory factor; one of the common polymorphisms in the IL-6 gene promoter (C-174G) was considered as risk factors for T2DM development [2]. IL10 is an anti-inflammatory cytokine protecting against T2DM and inflammation; several variants in the IL-10 gene promoter region have been identified and showed the association with the development of T2DM $[3,4]$. It is reported that TNF- $\alpha$ is a possible mediator of insulin resistance and diabetes since it inhibits insulin signaling and impairs its secretion [2-4]. One of the SNPs in TNF- $\alpha$ gene showed a twofold increase in transcriptional activity and an association of TNF- $\alpha$ SNPs with T2DM [2]. Genetic variants in some inflammatory 
factors associated with T2DM may provide a rationale for further studying their roles as biomarkers for disease early risk prediction and therapeutic targets for T2DM and related complications.

Although accumulating evidences support the pathological role of inflammatory cytokines in T2DM, most studies only focused on a few specific inflammatory factors and were done in relatively small population groups in a particular ethnic group. In our previous studies, we have explored the associations between few several inflammatory cytokines (e.g., CRP, immunoglobulin E (IgE), chymase, and tryptase) with prediabetes and T2DM and concluded that IgE and CRP are risk factors of prediabetes and T2DM only based on a small sample of cross-sectional study design [6, 7].

In this study, we extend the analysis of the role of proand anti-inflammatory cytokines in prediabetes and newly diagnosed T2DM based on a larger sample of cross-sectional study design, by measuring the levels of several proinflammatory cytokines (e.g., IgE, hs-CRP, IL-6, TNF- $\alpha$, and tryptase) and anti-inflammatory cytokines (e.g., IL-4, IL-10, and forkhead/winged helix transcription factor 3+ (Foxp3+)) in prediabetes and T2DM, and correlate them with other laboratory and clinical biochemical indicators. Our findings will lend support to the hypothesis that some specific inflammatory factors may play an etiological role in the pathogenesis of T2DM and also will offer new insights into the potential clinical value of these inflammatory factors as biomarkers for disease early risk prediction and therapeutic targets for T2DM and related complications.

\section{Materials and Methods}

2.1. Study Population. The study is part of the Diabetes Intervention Project (DIP) started in 2012 from School of Nursing and Medicine, Huzhou University, Zhejiang, China. From March to December 2012, a total of 7054 rural residents aged 50-75 years from eight rural communities in the city of Huzhou participated in physical examination. Based on the criteria of fasting plasma glucose (FPG) $<5.6 \mathrm{mmol} / \mathrm{L}$, $898(12.73 \%)$ were classified into prediabetes. During July to August 2013, after excluding subjects with known DM or receiving hypoglycaemic medications or with cardiovascular disease, cerebrovascular disease, malignant disease, chronic liver disease, or kidney failure, or those under medications, 825 cases of 898 prediabetes subjects and another 300 randomized sampling normal glucose subjects were invited for FPG, 2-hour oral glucose tolerance test (2 h OGTT), and haemoglobin Alc (HbAlc) tests as part of the prediabetes and T2DM screening. But only 560 subjects would participate in this study, according to the following clinical criteria based on FPG, 2 h OGTT, and HbAlc test: 219 (39.11\%) had normal glucose tolerance (NGT), 215 (38.39\%) were diagnosed as prediabetes subjects, and 126 (22.5\%) were diagnosed as T2DM subjects. This study was approved by the Huzhou City Ethics Committee and all subjects gave written, informed consent prior to participating in the study.
2.2. Data Collection. Trained staff interviewed participants using a self-designed questionnaire to obtain information on demographic characteristics and anthropometric and lifestyle variables. Physical activity assessments were performed using self-reported Total Energy Expenditure Questionnaire (TEEQ), a nine-step scale where every step was assigned a fixed value in terms of multiple of Metabolic Energy Turnover (MET) [8]. Anthropometric measurements (body height and weight, waist circumference (WC), hip circumference, and blood pressure) were attained at the initial screening visit. Two sitting blood pressure measurements were taken for each participant using a mercury sphygmomanometer according to a standard protocol. The mean of these two blood pressure measurements was used in the data analysis.

The biochemical parameters, including FPG, 2 h OGTT, $\mathrm{HbAlc}$, fasting insulin, plasma total cholesterol (TC), triglyceride (TG), low-density lipoprotein cholesterol (LDL-c), high-density lipoprotein cholesterol (HDL-c), hs-CRP, and $\operatorname{IgE}$, were measured in the Clinical Biochemistry Unit of Huzhou First Hospital, a teaching hospital of Huzhou University. The cytokine concentrations, including IL-6, TNF- $\alpha$, tryptase, IL-4, IL-10, and Foxp3+, were measured in patients sera using commercially available ELISA double antibody sandwich method assays (R\&D Systems), performed according to the manufacturer's instructions. Detection kits were produced by Wuhan Gene Biotech Co., Ltd.

2.3. Clinical Criteria. Diabetes and prediabetes were grouped according to American Diabetes Association 2010 (ADA 2010) criteria or HbAlc-based diagnosed criteria [9, 10]. Diabetes was classified with a fasting plasma glucose (FPG) $\geq$ $7.0 \mathrm{mmol} / \mathrm{L}$ or $2 \mathrm{~h} \mathrm{OGTT} \geq 11.1 \mathrm{mmol} / \mathrm{L}$ or $\mathrm{HbAlc} \geq$ $6.5 \%$, whereas prediabetes was defined as FPG $\geq 5.6$ and $<7.0 \mathrm{mmol} / \mathrm{L}$ or $2 \mathrm{~h} \mathrm{OGTT} \geq 7.8$ and $<11.1 \mathrm{mmol} / \mathrm{L}$ or $\mathrm{HbAlc} \geq$ $6.0 \%$ and $\mathrm{HbAlc}<6.5 \%$. Subjects were classified as having a normal glucose profile if FPG $<5.6 \mathrm{mmol} / \mathrm{L}$ and $2 \mathrm{~h}$ OGTT $<$ $7.8 \mathrm{mmol} / \mathrm{L}$ or $\mathrm{HbAlc}<6.0 \%$.

2.4. Statistical Analysis. The mean and standard deviation (mean $\pm \mathrm{SD}$ ) of continuous and normal distributional variables and median and quartile range of continuous but skewed distributional variables were used.

Body mass index (BMI) was calculated as weight in kilograms divided by the square of the height in meters $\left(\mathrm{kg} / \mathrm{m}^{2}\right)$. Waist-to-hip ratio (WHR) was calculated as waist divided by hip circumference. Homeostasis model assessment-insulin resistance (HOMA-IR) was calculated as value of FPG $\times$ value of fasting insulin/22.5 and homeostasis model assessment$\beta$ cell function (HOMA- $\beta$ ) was calculated as $20 \times$ value of fasting insulin/(FPG-3.5).

Based on China 2006 Blood Pressure Control Criteria and China Prevention and Treatment Classification Recommendation on Dyslipidemia [11], hypertension was defined as systolic blood pressure (SBP) and/or diastolic blood pressure $(\mathrm{DBP}) \geq 140 / 90 \mathrm{mmHg}$ or as receiving blood pressure lowering medications; high TG was defined as a fasting plasma TG $\geq 1.70 \mathrm{mmol} / \mathrm{L}$, low $\mathrm{HDL}-\mathrm{C}$ as a fasting $\mathrm{HDL}-\mathrm{C}$ 
$\leq 0.9 \mathrm{mmol} / \mathrm{L}$, high TC as TC $\geq 5.72 \mathrm{mmol} / \mathrm{L}$, and low LDL-C as a fasting LDL-C $\leq 3.64 \mathrm{mmol} / \mathrm{L}$. Based on China Obesity Task Group Recommendation [12], overweight was classified when a body mass index (BMI) $\geq 24 \mathrm{~kg} / \mathrm{m}^{2}$ and obesity was classified when a body mass index (BMI) $\geq 29 \mathrm{~kg} / \mathrm{m}^{2}$.

In analyzing the relationships of inflammatory cytokines to prediabetes or T2DM, IgE was classified as normal/abnormal according to upper quartiles (P75 = 34.0 IU/L); CRP was classified as normal/abnormal according to upper quartiles $(\mathrm{P} 75=1.0 \mathrm{mg} / \mathrm{L})$; tryptase was classified as normal/abnormal according to upper quartiles $(\mathrm{P} 75=1699.94 \mathrm{ng} / \mathrm{mL})$ and TNF- $\alpha$ was classified as normal/abnormal according to upper quartiles $(\mathrm{P} 75=325.14 \mathrm{pg} / \mathrm{mL})$; IL-4 was classified as normal/abnormal according to upper quartiles (P75 = $323.91 \mathrm{ng} / \mathrm{L}$ ); IL-10 was classified as normal/abnormal according to upper quartiles $(\mathrm{P} 75=256.22 \mathrm{ng} / \mathrm{L})$; FOXP3+ was classified as normal/abnormal according to upper quartiles $(\mathrm{P} 75=411.17 \mathrm{pg} / \mathrm{mL})$.

One-way analysis of covariance was used to test for differences in continuous distributional variables between three groups. The nonparametric Kruskal-Wallis test was used to test for differences in continuous but skewed distributional variables between two groups, and $\chi^{2}$ test was used to test differences in proportions between three groups.

Spearman correlation coefficients were calculated to evaluate associations between inflammatory cytokines and the traditional cardiovascular factors.

Binary logistic regression model was used to estimate the odds ratios (ORs) and 95\% CIs for prediabetes and T2DM according to dichotomy of inflammatory biomarkers concentration, using the lower values as the referent category. Considering the potential confounding factors, we applied 10 models to assess the association between biomarkers and prediabetes or T2DM, including unadjusted mode, age and sex-adjusted model, multivariable (age, sex, BMI, WHR, SBP, DBP, TC, TG, level of physical activity, dietary intake, alcohol intake, smoking status, presence or absence of family history of diabetes, hypertension, heart disease, stroke, and hypercholesterolemia) adjusted model, and multivariable combined with inflammatory biomarkers mutually adjusted model.

All statistical analysis was conducted using SPSS statistical software (version 19.0).

\section{Results}

The descriptive characteristics of 560 study participants were presented separately for participants with normal glucose tolerance, prediabetes, and T2DM (Table 1). A total of 215 were prediabetes, 126 were T2DM, and 219 were normal glucose subjects. Overall, except smoking status, alcohol use, disease family history, physical activity level, and dietary intake, all traditional vascular risk factors were worse in the PDG or the T2DMG patients than NGG subjects. Median levels of IgE in T2DMG subjects (40 IU/L) were significantly higher compared with NGG subjects $(18 \mathrm{IU} / \mathrm{L})(P<0.05)$ and with PDG subjects $(20 \mathrm{IU} / \mathrm{L})(P<0.05)$. Median levels of CRP in PDG subjects $(0.8 \mathrm{mg} / \mathrm{L})$ or T2DMG subjects $(1.5 \mathrm{mg} / \mathrm{L})$ were significantly higher compared with NGG subjects $(0.5 \mathrm{mg} / \mathrm{L})(P<0.05)$. Mean levels of tryptase in PDG subjects (mean \pm SD: $1545.36 \pm 291.45 \mathrm{ng} / \mathrm{mL}$ ) or T2DMG subjects (mean \pm SD: $1524.96 \pm 286.65 \mathrm{ng} / \mathrm{mL}$ ) were significantly higher compared with NGG subjects (mean \pm SD: $1481.21 \pm 271.44 \mathrm{ng} / \mathrm{mL})(P<0.05)$. Mean levels of IL-4 in PDG subjects (mean \pm SD: $303.70 \pm 56.84 \mathrm{ng} / \mathrm{L}$ ) or T2DMG subjects (mean \pm SD: $304.45 \pm 55.87 \mathrm{ng} / \mathrm{L}$ ) were significantly higher compared with NGG subjects (mean \pm SD: $283.45 \pm$ $52.50 \mathrm{ng} / \mathrm{L})(P<0.05)$. Mean levels of IL-10 in PDG subjects (mean \pm SD: $244.03 \pm 53.34 \mathrm{ng} / \mathrm{L}$ ) or T2DMG subjects (mean \pm SD: $265.04 \pm 40.42 \mathrm{ng} / \mathrm{L}$ ) were significantly higher compared with NGG subjects (mean \pm SD: $229.23 \pm 46.54 \mathrm{ng} / \mathrm{L})(P<$ $0.05)$. But there were no significant differences in IL-6, TNF$\alpha$, and Foxp3+ (Table 1).

Spearman correlation analysis between inflammatory cytokines and the traditional cardiovascular factors indicated that whether, in NGG, the PDG, or the T2DMG, there were significant relationships between most of the traditional cardiovascular factors and between most of inflammatory cytokines. However, there were seldom significant relationships between the traditional cardiovascular factors and inflammatory cytokines (Tables 2-4; Tables S1-S6) (in Supplementary Material available online at http://dx.doi.org/ 10.1155/2016/7965317).

After adjusting confounding factors by multivariable combined with inflammatory biomarkers mutually adjusted model, plasma IgE was associated with T2DM compared with NGG (OR (odds ratio): 3.46 (1.92-6.23, 95\% CI), $P<$ $0.001)$ or compared with PDG (OR: 2.57 (1.54-4.30, 95\% CI), $P<0.001$ ); plasma CRP was associated with PDG (OR: 2.30 (1.46-3.62, 95\% CI), $P<0.001$ ) or T2DM (OR: 16.24 (7.99-33.02, 95\% CI), $P<0.001)$ compared with NGG or T2DM (OR: 5.93 (3.29-10.72, 95\% CI), $P<0.001)$ compared with PDG; serum IL-4 was associated with PDG (OR: 1.68 $(1.05-2.69,95 \% \mathrm{CI}), P=0.031)$ or T2DM (OR: 1.94 (1.10$3.53,95 \% \mathrm{CI}), P=0.023)$ compared with NGG; serum IL10 was associated with PDG (OR: 2.13 (1.33-3.41, 95\% CI), $P=0.002)$ or T2DM (OR: $8.62(4.50-16.49,95 \% \mathrm{CI}), P<$ 0.001) compared with NGG or T2DM (OR: 3.04 (1.79-5.13, 95\% CI), $P<0.001$ ) compared with PDG (Table 5). Serum tryptase was associated with prediabetes (OR: 1.53 (1.01-2.32, $95 \% \mathrm{CI}), P=0.044)$ before adjustment and (OR: 1.63 (1.02$2.61,95 \% \mathrm{CI}), P=0.041$ ) after adjustment by multivariable + IL-4, compared with NGG. Serum IL-6, TNF- $\alpha$, and Foxp3+ were not associated with PDG or T2DM (Table 5).

\section{Discussion}

Our data showed increased levels of CRP, IL-4, IL-10, and tryptase in prediabetes subjects and increased levels of CRP, IL-4, and IL-10 in T2DM subjects compared with normal glucose subjects. Not all inflammatory cytokines in our study were in agreement with previous findings.

With the associations between inflammatory cytokines (e.g., IL-6, TNF- $\alpha$, and hs-CRP) and insulin resistance, prediabetes or T2DM had been widely researched [1321]. Most studies found that subjects with insulin resistance, prediabetes, or T2DM had increased levels of IL-6, 
TABLE 1: Baseline characteristics of 560 subjects with different glucose status grouped according to fasting, postload glucose levels, and HbAlc.

\begin{tabular}{|c|c|c|c|c|}
\hline Variable & NGG $(n=219)$ & PDG $(n=215)$ & T2DMG $(n=126)$ & $P$ value \\
\hline Age (years) ${ }^{*}$ & $58.13 \pm 6.37$ & $59.31 \pm 6.86$ & $59.37 \pm 7.07$ & 0.122 \\
\hline Sex $(\%$, male $)$ & 47.0 & 40.5 & 40.5 & 0.310 \\
\hline $\operatorname{BMI}\left(\mathrm{kg} / \mathrm{m}^{2}\right)^{*}$ & $23.58 \pm 3.17$ & $25.11 \pm 3.51^{\dagger}$ & $24.55 \pm 3.15^{\ddagger}$ & $<0.001$ \\
\hline $\mathrm{WC}(\mathrm{cm})^{*}$ & $79.92 \pm 9.19$ & $85.00 \pm 9.89^{\dagger}$ & $83.85 \pm 8.90^{\ddagger}$ & $<0.001$ \\
\hline $\mathrm{WHR}^{*}$ & $0.84 \pm 0.06$ & $0.87 \pm 0.05^{\dagger}$ & $0.87 \pm 0.06^{\ddagger}$ & $<0.001$ \\
\hline Smoking status (\%) & & & & 0.071 \\
\hline Current & 63.9 & 28.8 & 7.3 & - \\
\hline Never & 73.0 & 19.1 & 7.9 & - \\
\hline Past & 63.0 & 31.7 & 7.9 & - \\
\hline Alcohol use (in the past 12 months) (\%, drinker) & 25.1 & 17.2 & 22.2 & 0.130 \\
\hline History of diabetes (\%, yes) & 6.8 & 12.6 & 29.4 & $<0.001$ \\
\hline History of myocardial infarction (\%, yes) & 0.9 & 0.9 & 2.4 & 0.493 \\
\hline History of high blood pressure (\%, yes) & 15.1 & 14.0 & 18.3 & 0.689 \\
\hline History of stroke (\%, yes) & 4.6 & 5.6 & 4.8 & 0.731 \\
\hline History of dyslipidemia (\%, yes) & 8.7 & 6.5 & 13.5 & 0.360 \\
\hline Physical activity (MET/week)* & $440.47 \pm 146.79$ & $447.92 \pm 151.39$ & $427.49 \pm 152.15$ & 0.480 \\
\hline Dietary intake (\%, excess energy intake) & 74.9 & 72.1 & 73.0 & 0.800 \\
\hline Carbohydrate intake (\%) & & & & 0.740 \\
\hline$<55 \%$ of total energy intake & 56.6 & 54.9 & 50.8 & - \\
\hline $55-65 \%$ of total energy intake & 24.2 & 24.2 & 23.8 & - \\
\hline$>65 \%$ of total energy intake & 19.2 & 20.9 & 25.4 & - \\
\hline Fat intake $(\%)$ & & & & 0.005 \\
\hline$<20 \%$ of total energy intake & 11.9 & 20.0 & 23.8 & - \\
\hline $20-25 \%$ of total energy intake & 41.1 & 38.1 & 46.8 & - \\
\hline$>25 \%$ of total energy intake & 47.0 & 49.1 & 29.4 & - \\
\hline Protein intake (\%) & & & & 0.529 \\
\hline$<60 \%$ of total energy intake & 16.9 & 11.2 & 12.7 & \\
\hline $60-65 \%$ of total energy intake & 29.7 & 31.6 & 31.7 & \\
\hline$>65 \%$ of total energy intake & 53.4 & 57.2 & 55.6 & \\
\hline $\mathrm{FPG}(\mathrm{mmol} / \mathrm{L})^{* *}$ & $5.17(4.94-5.34)$ & $5.97(5.74-6.20)^{\dagger}$ & $7.72(7.35-8.89)^{\ddagger, \S}$ & $<0.001$ \\
\hline $2 \mathrm{~h} \mathrm{OGTT}(\mathrm{mmol} / \mathrm{L})^{*}$ & $5.35 \pm 1.08$ & $7.64 \pm 1.48^{\dagger}$ & $12.16 \pm 1.55^{\ddagger, \S}$ & $<0.001$ \\
\hline $\operatorname{HbAlc}(\%)^{*}$ & $5.06 \pm 0.80$ & $5.20 \pm 1.03$ & $6.64 \pm 1.64^{\ddagger, \S}$ & $<0.001$ \\
\hline Fasting insulin $(\mathrm{mU} / \mathrm{L})^{* *}$ & $7.0(6.55-7.36)$ & $7.36(6.89-8.70)^{\dagger}$ & $10.10(8.54-13.7)^{\ddagger, \S}$ & $<0.001$ \\
\hline HOMA-IR $^{* *}$ & $1.60(1.42-1.73)$ & $2.04(1.81-2.32)^{\dagger}$ & $3.64(2.93-4.58)^{\ddagger, \S}$ & $<0.001$ \\
\hline HOMA- $\beta^{* *}$ & $84.14(72.72-99.79)$ & $60.27(52.46-70.64)^{\dagger}$ & $48.67(32.96-66.35)^{\ddagger, \S}$ & $<0.001$ \\
\hline $\mathrm{SBP}(\mathrm{mmHg})^{*}$ & $121.74 \pm 20.01$ & $130.94 \pm 23.61^{\dagger}$ & $130.49 \pm 18.90^{\ddagger}$ & $<0.001$ \\
\hline $\mathrm{DBP}(\mathrm{mmHg})^{*}$ & $76.46 \pm 9.97$ & $80.53 \pm 11.29^{\dagger}$ & $77.83 \pm 8.31^{\S}$ & $<0.001$ \\
\hline $\mathrm{TC}(\mathrm{mmol} / \mathrm{L})^{*}$ & $4.85 \pm 0.84$ & $5.00 \pm 0.90^{\dagger}$ & $5.24 \pm 1.12^{\ddagger}$ & 0.001 \\
\hline $\mathrm{TG}(\mathrm{mmol} / \mathrm{L})^{* *}$ & $1.33(1.04-1.94)$ & $1.72(1.30-2.44)^{\dagger}$ & $1.95(1.31-3.17)^{\ddagger}$ & $<0.001$ \\
\hline HDL-c $(\mathrm{mmol} / \mathrm{L})^{*}$ & $1.29 \pm 0.32$ & $1.20 \pm 0.30^{\dagger}$ & $1.16 \pm 0.28^{\ddagger}$ & $<0.001$ \\
\hline $\mathrm{LDL}-\mathrm{c}(\mathrm{mmol} / \mathrm{L})^{*}$ & $2.85 \pm 0.75$ & $2.80 \pm 0.92$ & $2.90 \pm 1.04$ & 0.613 \\
\hline $\operatorname{IgE}(\mathrm{IU} / \mathrm{L})^{* *}$ & $18(7-34)$ & $20(7-42.5)$ & $40(16-64)^{\ddagger, \S}$ & $<0.001$ \\
\hline hs-CRP $(\mathrm{mg} / \mathrm{L})^{* *}$ & $0.5(0.3-1.0)$ & $0.8(0.4-2.0)^{\dagger}$ & $1.50(1.00-2.40)^{\ddagger, \S}$ & $<0.001$ \\
\hline IL-6 (ng/L) ${ }^{*}$ & $58.56 \pm 12.66$ & $60.92 \pm 12.82$ & $60.39 \pm 10.28$ & 0.117 \\
\hline
\end{tabular}


TABle 1: Continued.

\begin{tabular}{|c|c|c|c|c|}
\hline Variable & $\operatorname{NGG}(n=219)$ & PDG $(n=215)$ & T2DMG $(n=126)$ & $P$ value \\
\hline TNF- $\alpha(\mathrm{pg} / \mathrm{mL})^{*}$ & $284.94 \pm 61.17$ & $290.13 \pm 68.22$ & $295.37 \pm 57.25$ & 0.326 \\
\hline Tryptase $(\mathrm{ng} / \mathrm{mL})^{*}$ & $1481.21 \pm 271.44$ & $1545.36 \pm 291.45^{\dagger}$ & $1524.96 \pm 286.65^{\ddagger}$ & 0.036 \\
\hline IL-4 (ng/L) ${ }^{*}$ & $283.45 \pm 52.50$ & $303.70 \pm 56.84^{\dagger}$ & $304.45 \pm 55.87^{\ddagger}$ & $<0.001$ \\
\hline IL-10 (ng/L) ${ }^{*}$ & $229.23 \pm 46.54$ & $244.03 \pm 53.34^{\dagger}$ & $265.04 \pm 40.42^{\ddagger, \S}$ & $<0.001$ \\
\hline Foxp3+ $(\mathrm{pg} / \mathrm{mL})^{*}$ & $364.22 \pm 72.27$ & $367.26 \pm 24.46$ & $356.18 \pm 83.12$ & 0.418 \\
\hline
\end{tabular}

T2DM: type 2 diabetes mellitus; NGG: normal glucose group; PDG: prediabetes group; T2DMG: T2DM group; BMI: body mass index; WC: waist circumference; WHR: waist hip ratio; HOMA-IR: homeostasis model assessment-insulin resistance; HOMA- $\beta$ : homeostasis model assessment- $\beta$ cell function; FPG: fasting plasma glucose; $2 \mathrm{~h}$ OGTT: 2-hour oral glucose tolerance test; HbAlc: haemoglobin Alc; SBP: systolic blood pressure; DBP: diastolic blood pressure; TC: total cholesterol; TG: triglyceride; LDL-c: low-density lipoprotein cholesterol; HDL-c: high-density lipoprotein cholesterol; IgE: immunoglobulin E; hsCRP: hypersensitivity C-reactive protein; TNF- $\alpha$ : tumor necrosis factor; IL-6: interleukin-6; IL-4: interleukin-4; IL-10: interleukin-10; Foxp3+: forkhead/winged helix transcription factor $3+$.

${ }^{*}$ Variable is described using mean and standard deviation. ${ }^{* *}$ Variable is described using median and interquartile range. ${ }^{\dagger} P<0.05$, PDG compared with the NGG group; ${ }^{\ddagger} P<0.05$, DMG compared with the NGG group. ${ }^{\circledR} P<0.05$, T2DMG compared with the PDG group.

TABLE 2: Spearman correlation coefficients between cardiovascular factors in normal glucose group.

\begin{tabular}{|c|c|c|c|c|c|c|c|c|c|}
\hline & TC & TG & HDL_C & LDL_c & HOMA-IR & HOMA- $\beta$ & BMI & WHR & SBP \\
\hline TC & 1 & & & & & & & & \\
\hline TG & $0.321^{* *}$ & 1 & & & & & & & \\
\hline HDL_C & $-0.298^{* *}$ & $-.0363^{* *}$ & 1 & & & & & & \\
\hline LDL & $0.878^{* *}$ & 0.098 & 0.107 & 1 & & & . & & \\
\hline HOMA-IR & 0.062 & 0.042 & -0.120 & 0.036 & 1 & & . & & . \\
\hline HOMA- $\beta$ & -0.094 & $-0.137^{*}$ & 0.096 & -0.102 & $-0.140^{*}$ & 1 & & & \\
\hline BMI & $0.203^{* *}$ & $0.374^{* *}$ & $-0.279^{* *}$ & $0.209^{* *}$ & 0.062 & $-0.213^{* *}$ & 1 & & \\
\hline WHR & 0.029 & $0.363^{* *}$ & $-0.386^{* *}$ & 0.054 & 0.069 & -0.112 & $0.552^{* *}$ & 1 & . \\
\hline SBP & $0.184^{* *}$ & $0.144^{*}$ & -0.014 & $0.161^{*}$ & 0.053 & -0.124 & $0.284^{* *}$ & $0.252^{* *}$ & 1 \\
\hline DBP & $0.166^{*}$ & $0.220^{* *}$ & -0.105 & $0.148^{*}$ & 0.057 & -0.074 & $0.406^{* *}$ & $0.335^{* *}$ & $0.716^{* *}$ \\
\hline
\end{tabular}

TC: total cholesterol; TG: triglyceride; LDL-c: low-density lipoprotein cholesterol; HDL-c: high-density lipoprotein cholesterol; HOMA-IR: homeostasis model assessment-insulin resistance; HOMA- $\beta$ : homeostasis model assessment- $\beta$ cell function; BMI: body mass index; WHR: waist hip ratio; SBP: systolic blood pressure; DBP: diastolic blood pressure.

${ }^{*}$ Data on all subjects without missing values for all of these variables. ${ }^{*} P<0.05 .{ }^{* *} P<0.01$.

TNF- $\alpha$, and hs-CRP [13-16]. A study reported that high levels of inflammatory cytokines appeared in early stage of T2DM and were capable of predicting the development of type 2 diabetes through diminishing insulin sensitivity [14]. But a recent study showed decreased levels of IL- 6 and TNF- $\alpha$ in T2DM compared to healthy controls [17]. The author in this paper interpreted that this discrepancy could be attributed to duration of the diseases, small sample size, and the differences in age and sex of the studied groups [17]. Elevated plasma levels of hs-CRP in prediabetes and T2DM subjects have been demonstrated in this paper (Tables 1 and $5)$, our previous studies, and other studies [6, 7, 14-21]. Our data showed that mean levels of TNF- $\alpha$ or IL-6 in PDG or T2DMG subjects were higher but insignificant compared with NGG subjects (Tables 1 and 5), which could be explained by the differences of some incompletely measured residual confounding factors or inflammation-related diseases (e.g., rheumatoid arthritis (RA) or osteoarthritis (OA)) or allergies in the studied groups.

IgE stimulation during allergic reactions and infections is the natural defense mechanism. It also plays a crucial role in the pathophysiology of T2DM $[6,7]$. This current study demonstrated that plasma IgE levels strongly correlated with T2DM (Table 5), which was in agreement with our previous studies [6,7]. Further large population-based prospective studies are warranted to assess the role of IgE in T2DM.

IL-4 was major anti-inflammatory cytokine and had been proposed to play a crucial role in the pathophysiology of T2DM, and several candidate genes have been identified [22]. Our data showed that serum IL-4 was associated with PDG or T2DM (Tables 1 and 5).

IL-10 was anti-inflammatory cytokine and has been shown to improve impaired insulin signaling [23], prevent the development of IL-6 [24], inhibit NADPH oxidase [25], prevent pancreatic beta cell destruction [26], and play an important role in modulation of cardiovascular insulin resistance [23-26]. Two studies indicated that low IL-10 level was associated with high HbAlc and serum IL-10 level may be one of the predictors of glycemia $[27,28]$. Increased level of IL-10 in prediabetes and T2DM subjects in our study was in disagreement with these findings [2,26-28], which could be explained by high levels of inflammatory cytokines appearing in early stage of T2DM $[14,17]$. 
TABLE 3: Spearman correlation coefficients between inflammatory markers in normal glucose group.

\begin{tabular}{lcccccc}
\hline & IgE & CRP & IL-4 & IL-6 & IL-10 & Foxp3+ \\
\hline IgE & 1 & & & & \\
CRP & 0.117 & 1 & & & \\
IL-4 & 0.059 & $-0.174^{* *}$ & 1 & $\cdot$ & & \\
IL-6 & 0.026 & 0.06 & $0.303^{* *}$ & 1 & & \\
IL-10 & 0.087 & -0.012 & $0.272^{* *}$ & $0.259^{* *}$ & 1 & 1 \\
Foxp3+ & 0.071 & -0.066 & $0.211^{* *}$ & $0.245^{* *}$ & $0.430^{* *}$ & $0.458^{* *}$ \\
Tryptase & -0.009 & -0.106 & $0.176^{* *}$ & $0.188^{* *}$ & $0.302^{* *}$ & 1 \\
TNF- $\alpha$ & -0.052 & $-0.173^{*}$ & 0.057 & 0.049 & 0.08 & 0.085 \\
\hline
\end{tabular}

IgE: immunoglobulin E; hs-CRP: hypersensitivity C-reactive protein; IL-4: interleukin-4; IL-6: interleukin-6; IL-10: interleukin-10; Foxp3+: forkhead/winged helix transcription factor 3+; TNF- $\alpha$ : tumor necrosis factor.

${ }^{*}$ Data on all subjects without missing values for all of these variables. ${ }^{*} P<0.05$. ${ }^{* *} P<0.01$.

TABLE 4: Spearman correlation coefficients between inflammatory markers and cardiovascular factors in normal glucose group.

\begin{tabular}{lcccccccc}
\hline & IgE & CRP & IL-4 & IL-6 & IL-10 & Foxp3 & Tryptase & TNF- $\alpha$ \\
\hline TC & -0.087 & 0.007 & 0.038 & -0.083 & -0.031 & -0.016 & $0.138^{*}$ & $0.163^{*}$ \\
TG & 0.020 & 0.122 & 0.048 & 0.023 & 0.073 & 0.052 & 0.077 & 0.111 \\
HDL-c & 0.017 & $-0.146^{*}$ & -0.085 & $-0.136^{*}$ & -0.031 & 0.050 & 0.065 & 0.082 \\
LDL-c & -0.043 & -0.001 & 0.089 & -0.001 & -0.026 & -0.027 & 0.115 & 0.111 \\
HOMA-IR & 0.012 & 0.102 & 0.093 & -0.003 & 0.007 & -0.114 & -0.085 \\
HOMA- $\beta$ & 0.030 & 0.092 & -0.006 & 0.053 & -0.055 & -0.047 & 0.014 & -0.068 \\
BMI & 0.037 & 0.001 & -0.006 & -0.040 & 0.026 & 0.057 & 0.028 \\
WHR & -0.038 & -0.042 & $0.146^{*}$ & 0.106 & 0.108 & 0.126 & 0.095 \\
SBP & 0.091 & 0.024 & 0.000 & -0.071 & -0.003 & 0.041 & 0.072 \\
DBP & 0.132 & 0.043 & 0.045 & -0.024 & -0.045 & 0.026 & -0.028 \\
\hline
\end{tabular}

TC: total cholesterol; TG: triglyceride; LDL-c: low-density lipoprotein cholesterol; HDL-c: high-density lipoprotein cholesterol; HOMA-IR: homeostasis model assessment-insulin resistance; HOMA- $\beta$ : homeostasis model assessment- $\beta$ cell function; BMI: body mass index; WHR: waist hip ratio; SBP: systolic blood pressure; DBP: diastolic blood pressure; IgE: immunoglobulin E; hs-CRP: hypersensitivity C-reactive protein; IL-4: interleukin-4; IL-6: interleukin-6; IL-10: interleukin-10; Foxp3+: forkhead/winged helix transcription factor 3+; TNF- $\alpha$ : tumor necrosis factor.

${ }^{*}$ Data on all subjects without missing values for all of these variables. ${ }^{*} P<0.05$.

T regulatory (Treg) cells are a unique population of Tcells which play a crucial role in the maintenance of selftolerance and suppression of potentially inflammatory $\mathrm{T}$ cells [29]. Chronic low-grade inflammation in obesity and impaired insulin sensitivity has been associated with fewer Tregs in adipose tissue [29-31]. Our study did not prove the associations between FOXP3+ with the PDS or T2DM (Tables 1 and 5).

Mast cell tryptase is an important protease that has been implicated in cardiovascular diseases [32-34]. Our previous study did not demonstrate the association between plasma tryptase with prediabetes or T2DM [6,7]. But in this paper, our data indicated that tryptase was mildly associated with prediabetes (OR: $1.63(1.02-2.61,95 \% \mathrm{CI}), P=0.041)$ after adjustment by multivariable + IL-4, compared with NGG, which could be explained for the synergistic effect of IL-4.

Our data also showed that there were significant relationships between most of the traditional cardiovascular factors and between most of inflammatory cytokines. However, there were seldom significant relationships between the traditional cardiovascular factors and inflammatory cytokines (Tables 24; Tables S1-S6), which indicated that complex interactions could exist between these inflammatory cytokines or between cardiovascular factors [1-3, 20, 21].

Results of our study extend other evidences linking inflammatory cytokines to insulin resistance and risk of diabetes based on a larger sample of cross-sectional study design. Our findings further lend support to the hypothesis that some specific inflammatory factors may play an important role in the pathogenesis of T2DM and also offer new insights into the potential clinical value of these inflammatory factors as biomarkers for T2DM early prediction and treatment [13-17].

Our study has several limitations. We assessed the associations between few inflammatory cytokines and prediabetes and T2DM by means of plasma or serum biomarker only based on cross-sectional study design and cannot demonstrate that altered plasma or serum levels of inflammatory biomarkers are predictors of incident diabetes by large prospective cohort study. Our comprehensive assessment of diabetes risk factors allowed statistical control for important confounding factors in the pathogenesis of diabetes, but residual confounding could remain in the analysis. In particular, we did not consider potential inflammation-related diseases, such as RA or OA, which widely exist in the senior, 
TABLE 5: ORs of prediabetes and T2DM according to the inflammatory markers.

\begin{tabular}{|c|c|c|c|c|c|c|}
\hline & \multicolumn{6}{|c|}{ OR $(95 \% \mathrm{CI})$} \\
\hline & PDG versus NGG & $P$ & DMG versus NGG & $P$ & DMG versus PDG & $P$ \\
\hline \multicolumn{7}{|l|}{$\operatorname{IgE}$} \\
\hline Model 1 (unadjusted) ${ }^{\dagger}$ & $1.34(0.89-2.03)$ & 0.166 & $3.05(1.93-4.84)$ & $<0.001$ & $2.28(1.45-3.28)$ & $<0.001$ \\
\hline Model 2 (age and sex) $)^{\ddagger}$ & $1.35(0.89-2.65)$ & 0.156 & $3.11(1.95-4.95)$ & $<0.001$ & $2.29(1.46-3.59)$ & $<0.001$ \\
\hline Model 3 (multivariable) ${ }^{\S}$ & $1.41(0.89-2.24)$ & 0.147 & $3.51(1.96-6.29)$ & $<0.001$ & $2.55(1.52-4.25)$ & $<0.001$ \\
\hline Model 4 (multivariable + CRP) & $1.36(0.85-2.19)$ & 0.198 & $3.79(1.89-7.73)$ & $<0.001$ & $2.58(1.49-4.46)$ & 0.001 \\
\hline Model 5 (multivariable + tryptase) & $1.40(0.88-2.23)$ & 0.156 & $3.48(1.94-6.25)$ & $<0.001$ & $2.52(1.51-4.23)$ & $<0.001$ \\
\hline Model 6 (multivariable + IL-6) & $1.40(0.88-2.22)$ & 0.158 & $3.51(1.96-6.29)$ & $<0.001$ & $2.54(1.52-4.25)$ & $<0.001$ \\
\hline Model 7 (multivariable + TNF- $\alpha$ ) & $1.42(0.89-2.89)$ & 0.146 & $3.49(1.95-6.26)$ & $<0.001$ & $2.55(1.52-4.25)$ & $<0.001$ \\
\hline Model 8 (multivariable + IL-4) & $1.32(0.83-2.11)$ & 0.244 & $3.44(1.91-6.18)$ & $<0.001$ & $2.55(1.53-4.26)$ & $<0.001$ \\
\hline Model 9 (multivariable + IL-10) & $1.30(1.81-2.07)$ & 0.283 & $2.72(1.45-5.10)$ & 0.002 & $2.33(1.38-3.93)$ & 0.002 \\
\hline Model 10 (multivariable + Foxp3) & $1.39(0.87-2.21)$ & 0.167 & $3.46(1.92-6.23)$ & $<0.001$ & $2.57(1.54-4.30)$ & $<0.001$ \\
\hline \multicolumn{7}{|l|}{ CRP } \\
\hline Model 1 (unadjusted) ${ }^{\dagger}$ & $2.35(1.57-3.52)$ & $<0.001$ & $11.76(6.90-20.03)$ & $<0.001$ & $5.01(3.00-8.37)$ & $<0.001$ \\
\hline Model 2 (age and sex) $)^{\ddagger}$ & $2.32(1.55-3.49)$ & $<0.001$ & $11.70(6.84-20.02)$ & $<0.001$ & $5.11(3.04-8.57)$ & $<0.001$ \\
\hline Model 3 (multivariable) ${ }^{\varsigma}$ & $2.34(1.49-3.67)$ & $<0.001$ & $16.14(7.99-32.59)$ & $<0.001$ & $5.73(3.19-10.29)$ & $<0.001$ \\
\hline Model 4 (multivariable + IgE) & $2.31(1.47-3.64)$ & $<0.001$ & $17.23(8.17-36.33)$ & $<0.001$ & $5.81(3.19-10.59)$ & $<0.001$ \\
\hline Model 5 (multivariable + tryptase) & $2.31(1.47-3.63)$ & $<0.001$ & $16.17(7.99-32.70)$ & $<0.001$ & $5.81(3.23-10.48)$ & $<0.001$ \\
\hline Model 6 (multivariable + IL-6) & $2.34(1.49-3.68)$ & $<0.001$ & $16.30(7.99-32.59)$ & $<0.001$ & $5.79(3.21-10.43)$ & $<0.001$ \\
\hline Model 7 (multivariable + TNF- $\alpha$ ) & $2.36(1.50-3.72)$ & $<0.001$ & $17.30(8.43-35.52)$ & $<0.001$ & $5.75(3.20-10.34)$ & $<0.001$ \\
\hline Model 8 (multivariable + IL-4) & $2.23(1.41-3.51)$ & 0.001 & $17.34(8.39-35.86)$ & $<0.001$ & $5.87(3.24-10.61)$ & $<0.001$ \\
\hline Model 9 (multivariable + IL-10) & $2.25(1.42-3.54)$ & 0.001 & $17.35(8.24-35.74)$ & $<0.001$ & $5.79(3.16-10.59)$ & $<0.001$ \\
\hline Model 10 (multivariable + Foxp3) & $2.30(1.46-3.62)$ & $<0.001$ & $16.24(7.99-33.02)$ & $<0.001$ & $5.93(3.29-10.72)$ & $<0.001$ \\
\hline \multicolumn{7}{|l|}{ Tryptase } \\
\hline Model 1 (unadjusted) ${ }^{\dagger}$ & $1.53(1.01-2.32)$ & 0.044 & $1.15(0.70-1.88)$ & 0.588 & $0.75(0.46-1.21)$ & 0.237 \\
\hline Model 2 (age and sex) $)^{\ddagger}$ & $1.55(0.99-2.29)$ & 0.055 & $1.21(0.68-1.85)$ & 0.653 & $0.75(0.46-1.21)$ & 0.236 \\
\hline Model 3 (multivariable) ${ }^{\S}$ & $1.57(0.99-2.50)$ & 0.057 & $1.35(0.73-2.47)$ & 0.336 & $0.75(0.44-1.29)$ & 0.305 \\
\hline Model 4 (multivariable + IgE) & $1.56(0.98-2.45)$ & 0.06 & $1.32(0.66-2.36)$ & 0224 & $0.78(0.45-1.36)$ & 0.485 \\
\hline Model 5 (multivariable + CRP) & $1.52(0.95-2.44)$ & 0.082 & $1.34(0.66-2.73)$ & 0.417 & $0.71(0.40-1.25)$ & 0.235 \\
\hline Model 6 (multivariable + IL-6) & $1.22(0.74-2.00)$ & 0.436 & $1.39(0.74-2.61)$ & 0.306 & $0.83(0.47-1.47)$ & 0.527 \\
\hline Model 7 (multivariable + TNF- $\alpha$ ) & $1.47(0.90-2.38)$ & 0.126 & $1.28(0.68-2.41)$ & 0.440 & $0.71(0.40-1.27)$ & 0.246 \\
\hline Model 8 (multivariable + IL-4) & $1.63(1.02-2.61)$ & 0.041 & $1.26(0.67-2.30)$ & 0.484 & $0.73(0.42-1.26)$ & 0.263 \\
\hline Model 9 (multivariable + IL-10) & $1.36(0.84-2.19)$ & 0.213 & $0.93(0.47-1.84)$ & 0.841 & $0.64(0.37-1.12)$ & 0.117 \\
\hline Model 10 (multivariable + Foxp3) & $1.50(0.92-2.44)$ & 0.107 & $1.21(0.58-2.51)$ & 0.612 & $0.77(0.41-1.43)$ & 0.399 \\
\hline \multicolumn{7}{|l|}{ IL-6 } \\
\hline Model 1 (unadjusted) ${ }^{\dagger}$ & $1.37(0.91-2.08)$ & 0.136 & $0.85(0.51-1.42)$ & 0.534 & $0.62(0.37-1.03)$ & 0.062 \\
\hline Model 2 (age and sex) $)^{\ddagger}$ & $1.36(0.90-2.07)$ & 0.146 & $0.86(0.51-1.44)$ & 0.560 & $0.62(0.37-1.03)$ & 0.062 \\
\hline Model 3 (multivariable) ${ }^{\S}$ & $1.37(0.86-2.19)$ & 0.188 & $0.97(0.51-1.85)$ & 0.922 & $0.68(0.39-1.18)$ & 0.169 \\
\hline Model 4 (multivariable $+\operatorname{IgE}$ ) & $1.36(0.85-2.18)$ & 0.202 & $1.01(0.52-1.96)$ & 0.985 & $0.68(0.40-1.20)$ & 0.188 \\
\hline Model 5 (multivariable + CRP) & $1.37(0.85-2.22)$ & 0.193 & $0.99(0.46-2.11)$ & 0.977 & $0.64(0.36-1.18)$ & 0.159 \\
\hline Model 6 (multivariable + tryptase) & $1.22(0.74-2.00)$ & 0.436 & $0.88(0.45-1.73)$ & 0.720 & $0.72(0.40-1.29)$ & 0.264 \\
\hline Model 7 (multivariable + TNF- $\alpha$ ) & $1.41(0.88-2.27)$ & 0.157 & $0.95(0.50-1.82)$ & 0.876 & $0.67(0.38-1.17)$ & 0.161 \\
\hline Model 8 (multivariable + IL-4) & $1.25(0.77-2.02)$ & 0.374 & $0.85(0.43-1.65)$ & 0.624 & $0.62(0.35-1.12)$ & 0.111 \\
\hline Model 9 (multivariable + IL-10) & $1.19(0.73-1.93)$ & 0.483 & $0.68(0.33-1.39)$ & 0.287 & $0.56(0.31-1.00)$ & 0.05 \\
\hline Model 10 (multivariable + Foxp3) & $0.68(0.39-1.20)$ & 0.183 & $0.91(0.47-1.75)$ & 0.769 & $0.68(0.39-1.20)$ & 0.183 \\
\hline \multicolumn{7}{|l|}{ TNF- $\alpha$} \\
\hline Model 1 (unadjusted) ${ }^{\dagger}$ & $1.29(0.85-2.97)$ & 0.239 & $1.24(0.76-2.02)$ & 0.390 & $0.96(0.59-1.53)$ & 0.866 \\
\hline Model 2 (age and sex) & $1.31(0.85-2.00)$ & 0.218 & $1.26(0.77-2.07)$ & 0.358 & $0.96(0.59-1.55)$ & 0.867 \\
\hline Model 3 (multivariable) $)^{\S}$ & $1.43(0.89-2.29)$ & 0.140 & $1.29(0.70-2.38)$ & 0.420 & $1.04(0.60-1.81)$ & 0.883 \\
\hline Model 4 (multivariable $+\operatorname{IgE}$ ) & $1.42(0.89-2.89)$ & 0.146 & $1.26(0.67-2.38)$ & 0.480 & $1.04(0.59-1.83)$ & 0.885 \\
\hline Model 5 (multivariable + CRP) & $1.46(0.90-2.37)$ & 0.127 & $1.83(0.87-3.85)$ & 0.111 & $0.94(0.52-1.68)$ & 0.829 \\
\hline
\end{tabular}


TABLE 5: Continued.

\begin{tabular}{|c|c|c|c|c|c|c|}
\hline & \multicolumn{6}{|c|}{ OR $(95 \% \mathrm{CI})$} \\
\hline & PDG versus NGG & $P$ & DMG versus NGG & $P$ & DMG versus PDG & $P$ \\
\hline Model 6 (multivariable + tryptase) & $1.27(0.77-2.09)$ & 0.347 & $1.20(0.63-2.28)$ & 0.572 & $1.19(0.66-2.15)$ & 0.570 \\
\hline Model 7 (multivariable + IL-6) & $1.41(0.88-2.27)$ & 0.157 & $1.29(0.70-2.40)$ & 0.414 & $1.10(0.63-1.91)$ & 0.751 \\
\hline Model 8 (multivariable + IL-4) & $1.35(0.84-2.18)$ & 0.218 & $1.20(0.64-2.25)$ & 0.568 & $1.02(0.58-1.78)$ & 0.944 \\
\hline Model 9 (multivariable + IL-10) & $1.27(0.77-2.05)$ & 0.352 & $1.24(0.56-2.14)$ & 0.652 & $0.89(0.51-1.58)$ & 0.694 \\
\hline Model 10 (multivariable + Foxp3) & $1.06(0.61-1.85)$ & 0.840 & $1.24(0.66-2.30)$ & 0.504 & $1.06(0.61-1.85)$ & 0.840 \\
\hline \multicolumn{7}{|l|}{ IL-4 } \\
\hline Model 1 (unadjusted) ${ }^{\dagger}$ & $1.90(1.27-2.86)$ & 0.002 & $2.26(1.42-3.59)$ & 0.001 & $1.19(0.76-1.85)$ & 0.456 \\
\hline Model 2 (age and sex) $)^{\ddagger}$ & $1.93(1.28-2.92)$ & 0.002 & $2.27(1.41-3.63)$ & 0.001 & $1.19(0.76-1.86)$ & 0.457 \\
\hline Model 3 (multivariable) ${ }^{\S}$ & $1.73(1.09-2.75)$ & 0.020 & $2.06(1.15-3.68)$ & 0.015 & $1.13(0.68-1.87)$ & 0.649 \\
\hline Model 4 (multivariable + IgE) & $1.67(1.05-2.66)$ & 0.030 & $1.98(1.10-3.58)$ & 0.023 & $1.14(0.68-1.90)$ & 0.630 \\
\hline Model 5 (multivariable + CRP) & $1.58(1.00-2.52)$ & 0.057 & $2.47(1.22-4.98)$ & 0.012 & $0.86(0.50-1.50)$ & 0.601 \\
\hline Model 6 (multivariable + tryptase) & $1.53(1.02-2.61)$ & 0.041 & $2.01(1.02-3.60)$ & 0.019 & $1.18(0.71-1.99)$ & 0.522 \\
\hline Model 7 (multivariable + IL-6) & $1.67(1.04-2.66)$ & 0.033 & $2.11(1.17-3.80)$ & 0.013 & $1.29(0.76-2.21)$ & 0.350 \\
\hline Model 8 (multivariable + TNF- $\alpha$ ) & $1.68(1.06-2.67)$ & 0.026 & $2.03(1.13-3.63)$ & 0.017 & $1.12(0.67-1.87)$ & 0.663 \\
\hline Model 9 (multivariable + IL-10) & $1.46(0.90-2.36)$ & 0.125 & $1.58(0.84-2.97)$ & 0.158 & $0.88(0.52-1.51)$ & 0.645 \\
\hline Model 10 (multivariable + Foxp3) & $1.68(1.05-2.69)$ & 0.031 & $1.94(1.10-3.53)$ & 0.023 & $1.15(0.69-1.92)$ & 0.601 \\
\hline \multicolumn{7}{|l|}{ IL-10 } \\
\hline Model 1 (unadjusted) ${ }^{\dagger}$ & $1.99(1.32-2.99)$ & 0.001 & $5.76(3.57-9.29)$ & $<0.001$ & $2.90(1.84-4.58)$ & $<0.001$ \\
\hline Model 2 (age and sex) $)^{\ddagger}$ & $1.03(1.00-1.06)$ & 0.060 & $6.07(3.72-9.91)$ & $<0.001$ & $2.92(1.84-4.62)$ & $<0.001$ \\
\hline Model 3 (multivariable) ${ }^{\S}$ & $2.17(1.37-3.46)$ & 0.001 & $8.61(4.51-16.41)$ & $<0.001$ & $3.03(1.79-5.12)$ & $<0.001$ \\
\hline Model 4 (multivariable + IgE) & $2.11(1.32-3.37)$ & 0.002 & $7.56(3.92-14.57)$ & $<0.001$ & $2.82(1.65-4.81)$ & $<0.001$ \\
\hline Model 5 (multivariable + CRP) & $2.07(1.29-3.31)$ & 0.002 & $7.33(3.27-13.68)$ & $<0.001$ & $3.06(1.73-5.39)$ & $<0.001$ \\
\hline Model 6 (multivariable + tryptase) & $2.05(1.28-3.29)$ & 0.003 & $8.70(4.52-16.73)$ & $<0.001$ & $3.21(1.18-5.48)$ & $<0.001$ \\
\hline Model 7 (multivariable + IL-6) & $2.11(1.32-3.38)$ & 0.002 & $8.79(4.12-16.04)$ & $<0.001$ & $3.28(1.92-5.60)$ & $<0.001$ \\
\hline Model 8 (multivariable + TNF- $\alpha$ ) & $2.10(1.31-3.36)$ & 0.002 & $8.66(3.99-15.86)$ & $<0.001$ & $3.07(1.81-5.22)$ & $<0.001$ \\
\hline Model 9 (multivariable + IL-4) & $1.98(1.23-3.20)$ & 0.005 & $8.86(4.11-15.06)$ & $<0.001$ & $3.11(1.81-5.33)$ & $<0.001$ \\
\hline Model 10 (multivariable + Foxp3) & $2.13(1.33-3.41)$ & 0.002 & $8.62(4.50-16.49)$ & $<0.001$ & $3.04(1.79-5.13)$ & $<0.001$ \\
\hline \multicolumn{7}{|l|}{ Foxp3+ } \\
\hline Model 1 (unadjusted) ${ }^{\dagger}$ & $1.35(0.89-2.06)$ & 0.162 & $1.10(0.67-1.81)$ & 0.702 & $0.82(0.50-1.33)$ & 0.415 \\
\hline Model 2 (age and sex) $)^{\ddagger}$ & $1.33(0.87-2.03)$ & 0.190 & $1.07(0.65-1.77)$ & 0.788 & $0.81(0.50-1.33)$ & 0.410 \\
\hline Model 3 (multivariable) ${ }^{\S}$ & $1.31(0.81-2.17)$ & 0.270 & $1.69(0.91-3.12)$ & 0.097 & $0.90(0.52-1.57)$ & 0.720 \\
\hline Model 4 (multivariable + IgE) & $1.35(0.84-2.17)$ & 0.211 & $1.61(0.85-3.04)$ & 0.148 & $0.84(0.48-1.48)$ & 0.551 \\
\hline Model 5 (multivariable + CRP) & $1.19(0.73-1.95)$ & 0.478 & $150(0.65-3.24)$ & 0.241 & $0.73(0.40-1.31)$ & 0.293 \\
\hline Model 6 (multivariable + tryptase) & $1.17(0.71-1.93)$ & 0.544 & $1.61(0.85-3.04)$ & 0.144 & $1.01(0.56-1.83)$ & 0.977 \\
\hline Model 7 (multivariable + IL-6) & $1.24(0.76-2.02)$ & 0.395 & $1.70(0.92-3.17)$ & 0.093 & $0.98(0.56-1.73)$ & 0.947 \\
\hline Model 8 (multivariable + TNF- $\alpha$ ) & $1.26(0.78-2.04)$ & 0.349 & $1.66(0.89-3.07)$ & 0.111 & $0.90(0.51-1.56)$ & 0.701 \\
\hline Model 9 (multivariable + IL-4) & $1.17(0.72-1.92)$ & 0.525 & $1.57(0.84-2.93)$ & 0.161 & $0.88(0.50-1.54)$ & 0.659 \\
\hline Model 10 (multivariable + IL-10) & $1.13(0.69-1.86)$ & 0.624 & $1.68(0.86-3.28)$ & 0.132 & $0.88(0.50-1.55)$ & 0.651 \\
\hline
\end{tabular}

ORs: odd ratios; T2DM: type 2 diabetes mellitus; TC: total cholesterol; TG: triglyceride; BMI: body mass index; WHR: waist hip ratio; SBP: systolic blood pressure; DBP: diastolic blood pressure; IgE: immunoglobulin E; hs-CRP: hypersensitivity C-reactive protein; IL-4: interleukin-4; IL-6: interleukin-6; IL-10: interleukin-10; Foxp3+: forkhead/winged helix transcription factor 3+; TNF- $\alpha$ : tumor necrosis factor.

Data are OR (95\% CI) unless otherwise indicated.

${ }^{\dagger}$ Model 1 was not adjusted for any variable.

${ }^{\ddagger}$ Model 2 was adjusted for age and sex.

\$ Model 3 was adjusted for age, sex, BMI, WHR, SBP, DBP, TC, TG, level of physical activity, dietary intake, alcohol intake, smoking status, presence or absence of family history of diabetes, hypertension, heart disease, stroke, and hypercholesterolemia. 
or allergies which are also very common among individuals, and these unmeasured residual confounding factors might result in discrepancies.

In conclusion, circulating inflammatory mediators, hsCRP, IgE, IL-4, IL-10, and tryptase, were positively associated with prediabetes or T2DM. Further large prospective studies are warranted to assess a temporal relation between baseline levels of inflammatory biomarkers and incidence of prediabetes or T2DM and its associated chronic diseases.

\section{Competing Interests}

The authors declare that there is no conflict of interests regarding the publication of this paper. The authors confirm that the mentioned received funding in the Acknowledgments did not lead to any conflict of interests regarding the publication of this paper.

\section{Acknowledgments}

The authors thank all the volunteers who participated in this study and the clinic staff members from the Huzhou First Hospital, Zhebei Clinical Medicine Hospital, and Huanzhu Street Community Health Service Center for their assistance in clinical data collections. This work was supported by grants from the Huzhou Municipal Science and Technology Agency (2012GS02) (Zhen Wang), the Zhejiang Province Natural science fund (LY13H070004) (Xu-Hui Shen), and the Zhejiang Province Science Technology Department Plan Projects (2015C33283) (Zhen Wang).

\section{References}

[1] A. Nadeem, S. Mumtaz, A. K. Naveed et al., "Gene-gene, geneenvironment, gene-nutrient interactions and single nucleotide polymorphisms of inflammatory cytokines," World Journal of Diabetes, vol. 6, no. 4, pp. 642-647, 2015.

[2] M. Banerjee and M. Saxena, "Genetic polymorphisms of cytokine genes in type 2 diabetes mellitus," World Journal of Diabetes, vol. 5, no. 4, pp. 493-504, 2014.

[3] A. Brunetti, E. Chiefari, and D. Foti, "Recent advances in the molecular genetics of type 2 diabetes mellitus," World Journal of Diabetes, vol. 5, no. 2, pp. 128-140, 2014.

[4] M. Saxena, N. Srivastava, and M. Banerjee, "Association of IL6 , TNF- $\alpha$ and IL-10 gene polymorphisms with type 2 diabetes mellitus," Molecular Biology Reports, vol. 40, no. 11, pp. 62716279, 2013.

[5] P. Arora, B. Garcia-Bailo, Z. Dastani et al., "Genetic polymorphisms of innate immunity-related inflammatory pathways and their association with factors related to type 2 diabetes," BMC Medical Genetics, vol. 12, article 95, 2011.

[6] Z. Wang, H. Zhang, X.-H. Shen et al., "Immunoglobulin e and mast cell proteases are potential risk factors of human prediabetes and diabetes mellitus," PLOS ONE, vol. 6, no. 12, Article ID e28962, 2011.

[7] Z. Wang, H. Zhang, X.-H. Shen et al., "Immunoglobulin E and mast cell proteases are potential risk factors of impaired fasting glucose and impaired glucose tolerance in humans," Annals of Medicine, vol. 45, no. 3, pp. 220-229, 2013.
[8] Y. T. Lagerros, L. A. Mucci, R. Bellocco, O. Nyrén, O. Bälter, and K. A. Bälter, "Validity and reliability of self-reported total energy expenditure using a novel instrument," European Journal of Epidemiology, vol. 21, no. 3, pp. 227-236, 2006.

[9] N. Alqahtani, W. A. G. Khan, M. H. Alhumaidi, and Y. A. A. R. Ahmed, "Use of glycated hemoglobin in the diagnosis of diabetes mellitus and pre-diabetes and role of fasting plasma glucose, oral glucose tolerance test," International Journal of Preventive Medicine, vol. 4, no. 9, pp. 1025-1029, 2013.

[10] D. E. Olson, M. K. Rhee, K. Herrick, D. C. Ziemer, J. G. Twombly, and L. S. Phillips, "Screening for diabetes and prediabetes with proposed A1C-based diagnostic criteria," Diabetes Care, vol. 33, no. 10, pp. 2184-2189, 2010.

[11] Y. Wu, R. Huxley, L. Li et al., "Prevalence, awareness, treatment, and control of hypertension in China: data from the China National Nutrition and Health Survey 2002," Circulation, vol. 118, no. 25, pp. 2679-2686, 2008.

[12] P.-H. Zhang, S.-F. Jiao, Y. Zhou et al., "Study on chronic disease related behavior and lifestyle in adults in Beijing, 2005," Chinese Journal of Epidemiology, vol. 28, no. 12, pp. 1162-1166, 2007.

[13] P. Marques-Vidal, F. Bastardot, R. Von Känel et al., "Association between circulating cytokine levels, diabetes and insulin resistance in a population-based sample (CoLaus study)," Clinical Endocrinology, vol. 78, no. 2, pp. 232-241, 2013.

[14] M. I. Schmidt, B. B. Duncan, A. R. Sharrett et al., "Markers of inflammation and prediction of diabetes mellitus in adults (Atherosclerosis Risk in Communities study): a cohort study," The Lancet, vol. 353, no. 9165, pp. 1649-1652, 1999.

[15] J. M. Guzmán-Flores, J. F. Muñoz-Valle, J. Sánchez-Corona et al., "Tumor necrosis factor-alpha gene promoter -308G/A and -238G/A polymorphisms in Mexican patients with type 2 diabetes mellitus," Disease Markers, vol. 30, no. 1, pp. 19-24, 2011.

[16] S. Tangvarasittichai, S. Pongthaisong, and O. Tangvarasittichai, "Tumor necrosis factor-A, interleukin-6, C-reactive protein levels and insulin resistance associated with type 2 diabetes in abdominal obesity women," Indian Journal of Clinical Biochemistry, vol. 31, no. 1, pp. 68-74, 2016.

[17] A. Al-Shukaili, S. AL-Ghafri, S. Al-Marhoobi, S. Al-Abri, J. Al-Lawati, and M. Al-Maskari, "Analysis of inflammatory mediators in type 2 diabetes patients," International Journal of Endocrinology, vol. 2013, Article ID 976810, 7 pages, 2013.

[18] G. Mavridis, E. Souliou, E. Diza et al., "Inflammatory cytokines in insulin-treated patients with type 2 diabetes," Nutrition, Metabolism and Cardiovascular Diseases, vol. 18, no. 7, pp. 471476, 2008.

[19] C. Sabanayagam, A. Shankar, S. C. Lim, J. Lee, E. S. Tai, and T. Y. Wong, "Serum C-reactive protein level and prediabetes in two Asian populations," Diabetologia, vol. 54, no. 4, pp. 767-775, 2011.

[20] X. Ye, G. Zong, X. Liu et al., "Development of a new risk score for incident type 2 diabetes using updated diagnostic criteria in middle-aged and older Chinese," PLoS ONE, vol. 9, no. 5, Article ID e97042, 2014.

[21] I. Isordia-Salas, M. E. Galván-Plata, A. Leaños-Miranda et al., "Proinflammatory and prothrombotic state in subjects with different glucose tolerance status before cardiovascular disease," Journal of Diabetes Research, vol. 2014, Article ID 631902, 9 pages, 2014.

[22] M. Hülsmeyer, C. Scheufler, and M. K. Dreyer, "Structure of interleukin 4 mutant E9A suggests polar steering in receptorcomplex formation," Acta Crystallographica Section D Biological Crystallography, vol. 57, no. 9, pp. 1334-1336, 2001. 
[23] A. R. Aroor, S. McKarns, V. G. Demarco, G. Jia, and J. R. Sowers, "Maladaptive immune and inflammatory pathways lead to cardiovascular insulin resistance," Metabolism: Clinical and Experimental, vol. 62, no. 11, pp. 1543-1552, 2013.

[24] M. Kassan, M. Galan, M. Partyka, M. Trebak, and K. Matrougui, "Interleukin-10 released by $\mathrm{CD} 4{ }^{+} \mathrm{CD} 25^{+}$natural regulatory $\mathrm{T}$ cells improves microvascular endothelial function through inhibition of NADPH oxidase activity in hypertensive mice," Arteriosclerosis, Thrombosis, and Vascular Biology, vol. 31, no. 11, pp. 2534-2542, 2011.

[25] K. Ohshima, M. Mogi, F. Jing et al., "Roles of interleukin 17 in angiotensin II type 1 receptor-mediated insulin resistance," Hypertension, vol. 59, no. 2, pp. 493-499, 2012.

[26] M. Saxena, C. C. Agrawal, H. K. Bid, and M. Banerjee, "An interleukin-10 gene promoter polymorphism (-592A/C) associated with type 2 diabetes: a North Indian study," Biochemical Genetics, vol. 50, pp. 549-559, 2012.

[27] A. B. Acharya, S. Thakur, and M. V. Muddapur, "Evaluation of serum interleukin-10 levels as a predictor of glycemic alteration in chronic periodontitis and type 2 diabetes mellitus," Journal of Indian Society of Periodontology, vol. 19, no. 4, pp. 388-392, 2015.

[28] A. B. Acharya, S. Thakur, and M. V. Muddapur, "J Indian effect of scaling and root planing on serum interleukin-10 levels and glycemic control in chronic periodontitis and type 2 diabetes mellitus," Journal of Indian Society of Periodontology, vol. 19, no. 2, pp. 188-193, 2015.

[29] G. Liu, H. Ma, L. Qiu et al., "Phenotypic and functional switch of macrophages induced by regulatory CD 4 CD25 T cells in mice," Immunology and Cell Biology, vol. 89, no. 1, pp. 130-142, 2011.

[30] S. Sun, Y. Ji, S. Kersten, and L. Qi, "Mechanisms of inflammatory responses in obese adipose tissue," Annual Review of Nutrition, vol. 32, pp. 261-286, 2012.

[31] M. Feuerer, L. Herrero, D. Cipolletta et al., "Lean, but not obese, fat is enriched for a unique population of regulatory $\mathrm{T}$ cells that affect metabolic parameters," Nature Medicine, vol. 15, no. 8, pp. 930-939, 2009.

[32] J. Sun, J. Zhang, J. S. Lindholt et al., "Critical role of mast cell chymase in mouse abdominal aortic aneurysm formation," Circulation, vol. 120, no. 11, pp. 973-982, 2009.

[33] J. Zhang, J. Sun, J. S. Lindholt et al., "Mast cell tryptase deficiency attenuates mouse abdominal aortic aneurysm formation," Circulation Research, vol. 108, no. 11, pp. 1316-1327, 2011.

[34] M. Xiang, J. Sun, Y. Lin et al., "Usefulness of serum tryptase level as an independent biomarker for coronary plaque instability in a Chinese population," Atherosclerosis, vol. 215, no. 2, pp. 494499, 2011. 


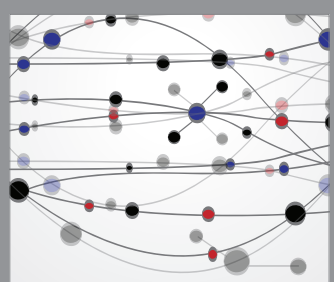

The Scientific World Journal
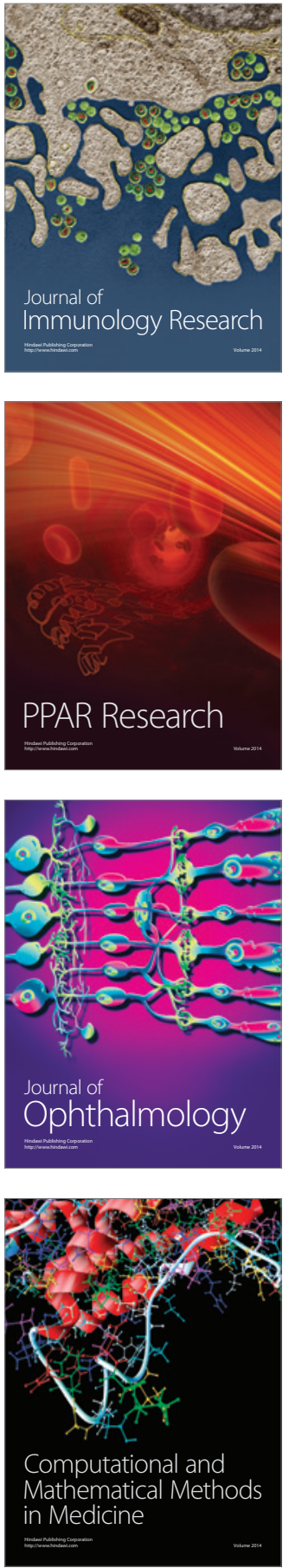

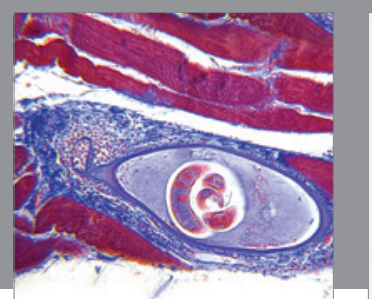

Gastroenterology Research and Practice

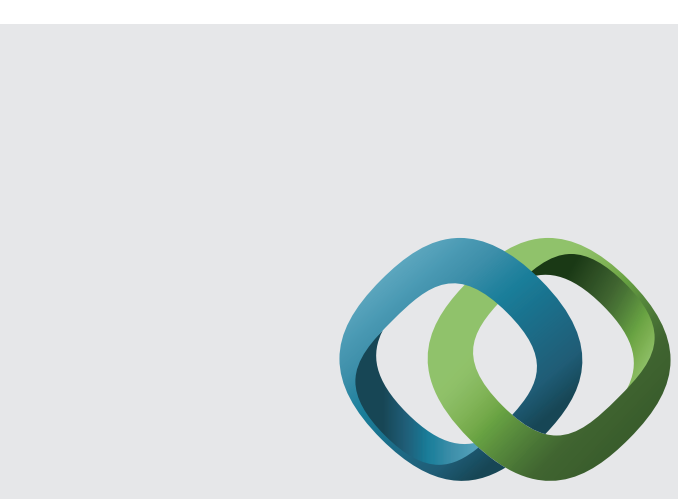

\section{Hindawi}

Submit your manuscripts at

http://www.hindawi.com
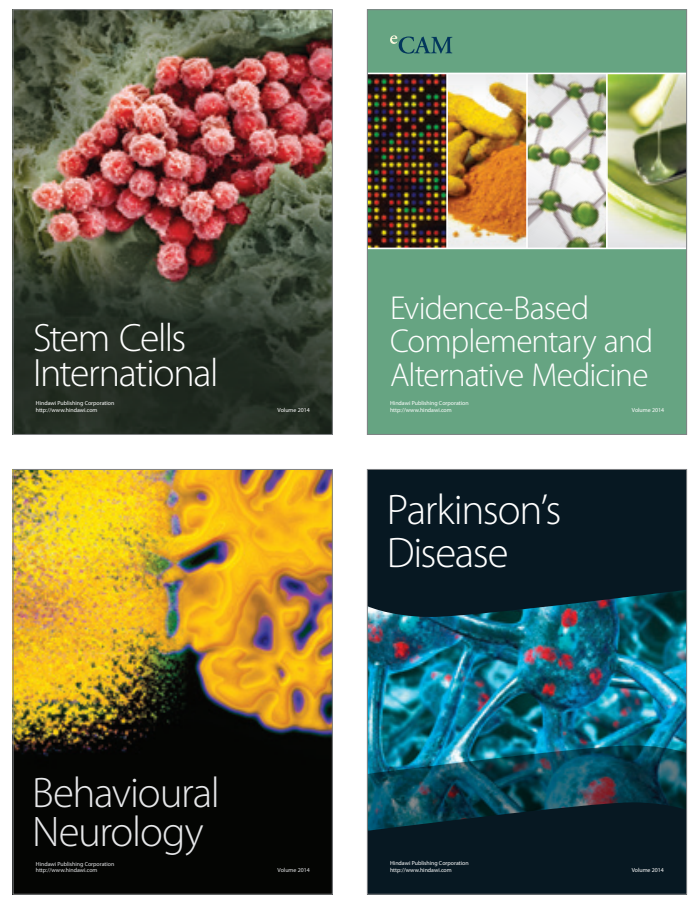
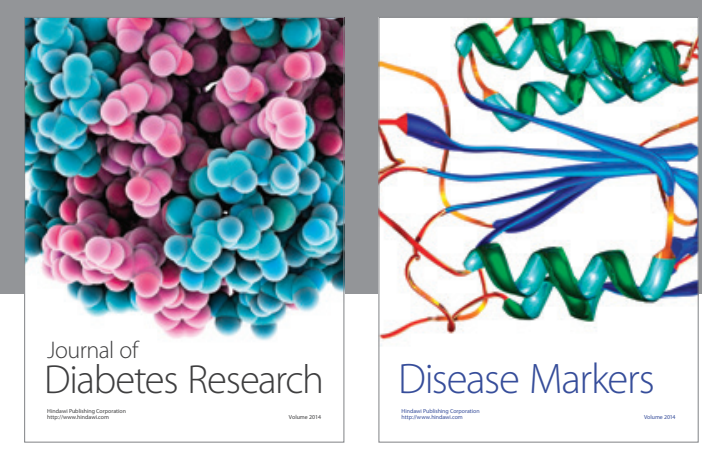

Disease Markers
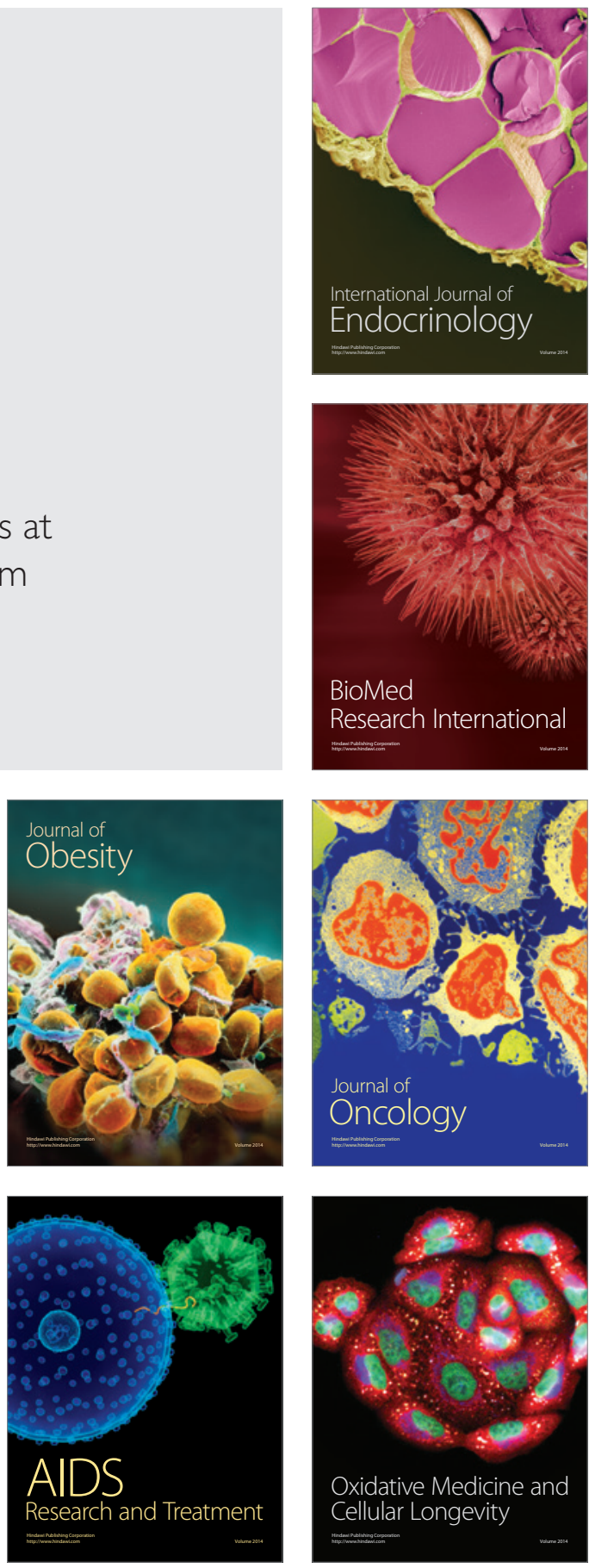